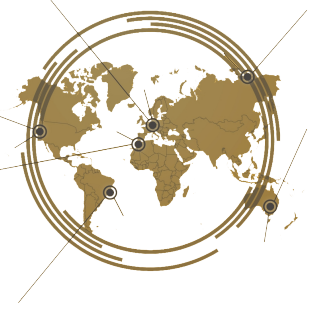

\title{
Online learning motivation for Aviation English: Attitude, readiness, and demographic factors
}

\author{
Laila Rochmawati*, Fatmawati Fatmawati, Meita Maharani Sukma, Imam Sonhaji \\ Politeknik Penerbangan Surabaya
}

Online learning is an ideal technological development that is created and improved according to technology within the present educational context. The purpose of this study was to find out motivation, attitude, and readiness, as well as demographic factors in online learning, applied linguistics in the Civil Aviation Polytechnic of Surabaya cadets. The instruments in this study were online learning motivation, online learning readiness and online learning attitudes Likert scale questions cumulated using quantitative method with multiple linear regression. This study utilized a group of 139 Diploma-3 Aeronautical Communication Officer and Diploma-3 Air Traffic Controller cadets. Study results mentioned that attitude to online learning, readiness of online learning, age, gender, and education are all important predictors of the motivation for education. The results showed that the level of education

and readiness of online learning were variables that have a considerable effect on motivation. The outcomes of this research cope with students' online learning motivation problems in Aviation English online learning.

Keywords: aviation English, attitude, online learning, readiness, motivation

\section{INTRODUCTION}

Online learning is a model of learning generated through electronic devices in digital format Panigrahi et al. (2018). The use of online learning in education includes the following steps :1) enhancement of learning quality through the use of online learning (use of communication and ICT) Nanayakkara (2007). Online learning is an ideal technological development that is created and improved according to technology within the present educational context Al-Rahmi (2019). The non-learning environment accepts and applies technology so quickly at different times. Many people still use apps or mobile devices in everyday and professional life to interact with their colleagues. It is because the use of this interactive device has many benefits and can be spent if necessary and costs. Besides an attractive form, it is also straightforward to operate, but it doesn't take long to learn by looking at someone who can already be used Wong et al. (2020).

Students' readiness to excel in online learning settings is also an essential element that the Institute needs to pay attention to Prior (2016) Hung (2010). Online learning provides cadets with the ability to learn anywhere and anytime. Cadets have greater flexibility about when and how they carry out their learning activities An (2018). Some cadets cannot participate in conventional learning programs due to external factors (including work, family commitment, campus proximity, and related policy involvement). 
Online learning can solve the limitations of conventional learning. Some of the skills required in learning with online media include knowledge of technology, time management and institutions, and online technology connections. Online learning does not require a long time and process to quickly and easily improve learning achievement Kolekar et al. (2018). The need for the involvement of learning institutions in online learning can increase the success of cadet learning outcomes. Learning institutions need to provide various forms of standard criteria for increasing graduation rates and learning efficiency, one of which is online learning. Students are more involved in the field of education Lieharyani et al. (2019).

Motivation has been a crucial factor for students to succeed in online learning Titrek et al. (2018). Online classes bring unique challenges for students, especially in terms of cadet motivation, and is one of the factors that affect students' ability to succeed academically in an online class Saeedi et al. (2019); Suri (2016). In the COVID-19 pandemic, ineffective online learning solutions may cause obstacles in achieving the vision of higher education on online learning and the desired learning performance. Practical outcomes in online learning allow students to be motivated to be successful, so that cadets must have the ability to interact with the learning environment either internally or externally Kaftan and Freund (2019). Physical distance constraints when studying online require better self-control to succeed.

Academic learning motivation requires complex solutions and contains various types of motivation. The reason for this is that every student has a unique incentive to be active in the online learning environment Ilgaz and Gülbahar (2015). Academic encouragement is key to being an online student. By providing a setting for students' motivation and psychological needs, theory of self-determination can provide insight into motivative learning Titrek et al. (2018); Durksen et al. (2016). The Academic Motivation Scale (AMS) evaluates online learning populations' types of motivation. The students ' motivation in online environments has several causes.

One common issue with online learning is that there are less online students than those who are expected to do so. Previous research has found that number and length of updates, topics read by them and the actions of the user are significantly predicted by the levels of students ' motivation Durksen et al. (2016); Çakır et al. (2019). Students' enthusiasm is a significant contributor to online learning. If universities do not discuss motivational questions, students may be affected by learning. One study identified five major impacts on student learning from the student's incentive to learn online low. The outcomes are commitment, perseverance, accomplishment, student learning aspirations and class learning satisfaction Kaftan and Freund (2019) Suri (2016). Teachers and curriculum planners are concerned with the attitude of students towards online learning and the application of technology online learning Çakır et al. (2019). Positive attitudes towards online learning are motivating and motivating on a scale can be calculated. Attitude to online learning have been influenced by job, class and previous exposure Prior (2016). Online learning preparedness is a factor that directly influences student motivation Harrison (2017). When students do not possess the skills to excel in online learning, an educational institution can not expect adequate encouragement or good results Gay (2016).

Attitude to online learning, readiness of online learning, and demographic factors are three types of potential factors affecting cadet motivation in on-line learning Suri (2016). Many students reject online learning solutions because they are prejudicial to the inefficiency of learning. The interest of the students in online learning is directly affected Parker (2018). The nature of cadets as specific learners can also be a concern because cadets often compare their demographic characteristics with the ease with which they use educational technologies Ilgaz and Gülbahar (2015). The study have found that demographics in their study are not the potential correlational factor Kebritchi et al. (2017). In subjects such as lessons, subjects or history, motivation was important for students.

The theory of self-determination is a general education theory which explains motivation of cadets in different contexts, through the core needs of cadets. The approach to selfdetermination offers two fundamental principles relating to the education sector. The first idea is to define three psychological requirements, such as autonomy, competence and communication, for the universal cadet. The second definition of self-determination theory is a structure to understand cadets' motivation in education Yilmaz (2017). The system has internal motivations as well as the external. This theory provides a means of evaluating the motivation of students in online learning. The self-determination principle serves as the foundation for building AMS Titrek et al. (2018). The tool is made up of questions grouped within the structure, based on various motivating forms, given by the principle of self-determination.

Students who engage in online learning have different levels of readiness and preparation (for example, online skills, selfdisconnect) that may affect their performance (degree, completion) Suri (2016). Institutional efforts may include providing students with resources to evaluate whether they are ready to take courses and to offer online training advice Yilmaz (2017). For instance, administrators or institutions can build up their students' readiness of online learning and create a support system for the success of their students. In addition to online learning institutions supporting online students, teaching efforts in promoting a cadet can include the creation of instructors' work to Wong et al. (2020).

Research can better inform this effort and overcome particular challenges that have emerged from the previous study. Past research challenges include: 1) developing instruments that are not precise; 2) not tested in full online higher education; 3) not examining relations with student outcomes, or; 4) not clearing or replenishing relationships with student outcomes. The instruments have been developed in previous tool reviews to create a reliable, valid, and comprehensive tool in student's readiness Yilmaz (2017), which is to be repeated and enhanced via inter agency research to identify vital factors 
affecting cadets' success.

Online learning is central to online learning, as this provides insights into the needs of one's people and best integrated into online learning design Buzdar et al. (2016). Online learning is the subfield of learning science. Also, especially concerned is the engagement of students in online learning environments Bovermann et al. (2018). Online Learning Readiness Scale (OLRS) has five dimensions: computer / web performance, independent learning, student control, enthusiasm for learning and online mandarin effectiveness Buzdar et al. (2016). This research uses OLRS to test the readiness of online learning as a potential indicator of the motivation to learn. The results of the study provide insights on the readiness for online learning and motivate them to learn online, and strengthen the relation between online readiness for learning and motivation for online learning Hung (2010); Yilmaz (2017). This study tested the motivation of learning, readiness, and attitude of online learning simultaneously. In contrast, previous research tested it separately. The findings of this study have an impact not only on cadets but also on the entire organization. This research focuses on the learning of applied linguistics in aviation because all of the basic knowledge of flight cadets is English based.

\section{METHODS}

Quantitative research was used in these survey methods for gathering the data from the cadets. The data needed for research questions contained four sections of 64 question items. Cadets were students in semi-military training colleges who were required after completing their education to work under the Ministry of Transportation. The participants completed the survey by accessing the survey through an online site, on the date specified for each selected class. Aviation Polytechnic cadets, including Diploma-3 Aeronautical Communication Officer and Diploma-3 Air Traffic Controller, form the population for this study. The sample was selected from the Aviation English language-learning classes based on population that have an online learning experience. The researchers were collected the data from a single survey, including four individual sections.

A collection of variables for this analysis will be discussed in each section. The first segment consists of demographic elements that allow participants to include basic information about themselves and their status as cadets. The second part is the segment online learning attitude, which tests the current views of the participants about online learning and its solution. The second part consists of six questions, using a Likerttype four-point scale. An updated version of the AMS contains the third component. The validity of AMS needs to be assessed against academic motivation. Test-recovery, confirmatory factor tests, internal accuracy by Cronbach alpha, and temporal stability were used to test the validity of this process. The OLRS provides a tool for evaluating students' readiness of online learning - to test the validity of this device through a confirmed factor analysis before the study begins online.

\section{RESULTS AND DISCUSSION}

This quantitative research uses survey methods to gather for each cadet the data needed for research questions containing four sections of 64 question items. The first part contains demographic items with 12 question items, which requires participants to provide some primary data about themselves and their status at the Surabaya Aviation Polytechnic. The second part is the online learning attitudes section with six items, which measures participants' current views on online learning and online learning solutions. The third part is the measurement of the academic motivation scale (AMS) to measure academic motivation. This instrument uses a 28 item Likert scale and ensures the validity of this instrument through confirmatory factor analysis, internal consistency through Cronbach alpha, and temporal stability through test-retest correlation Vallerand et al. (1992). The fourth section contains measurements of the Online Learning Readiness Scale (OLRS) to assess students' readiness for online learning with 18 Likert scale items. OLRS ensures this instrument's validity through confirmatory factor analysis and by having individuals with prior online learning experiences review the instrument Hung (2010).

Cadets are students in semi-military training colleges who are required after completing their education to work under the Ministry of Transportation. The theoretical structure considerations concentrate on the theory of self-determination regarding the issue of motivation for online learning and the influence of three online learning constructs. The effect of building online learning includes the readiness for the cadets to learn, attitudes and motivation. The seven variables included the readiness of online learning, attitude to online learning, rankings, years of service, age, gender and level of education. Aviation Polytechnic cadets, who participated in online learning on English for Aviation material, were the study population. Predictor variables are measured by means of survey instruments that combine two devices.

The quality and reliability of the information obtained in this study must, in theory, be assessed by quantitative analysis. Many studies have used different measures for the AMS and for the OLRS. Using the OLRS portion of this method means that the online learning experience was answered by the survey participants. The online attitude learning component is the only aspect of the data review that involves checking the validity and reliability of this report. The results of the system for analyzing data showed to classify the alpha of Cronbach $(\pi=0.87)$. Therefore, there is high reliability in the overall reliability of the online learning attitude segment. The online learning attitude instruments adjust with the validity facing achievement in mind. Multiple regression analysis includes three assumptions: normality, homogeneity, and the absence of multicollinearity. The first assumption test on multiple regressions is that vari- 
ance or homoscedasticity are homogeneous. The dispersion is helpful to monitor the homogeneity of the variance. Cutting plots are rendered using regular predictive values on uniform residues for the AMS variable score dependent; the outcome scatter plot is shown in Figure 1. There was no violation of the homogeneity principle based on the distance, as the points seem to scatter uniformly along the zero lines instead of having the funnel face outwards like scores distribution. The second test for inference is normality dependent on the residue of the normally distributed model. The standard waste histogram is shown in the Figure 2, and the residue is in the shape but not full of a bell curve. The normal cumulative distribution function found from the standard residue compared to the cumulative distribution function expected Figure 3. Since the plot tends to be only slightly deviating from the usual track, it is safe to conclude that there is normality. Figure $\mathbf{1}$ depicts the resulting scatter plot. Based on the scatter, there does not appear to violate the homogeneity assumption. The points seem to spread evenly around the zero lines instead of creating an outwardfacing funnel like a points' distribution.

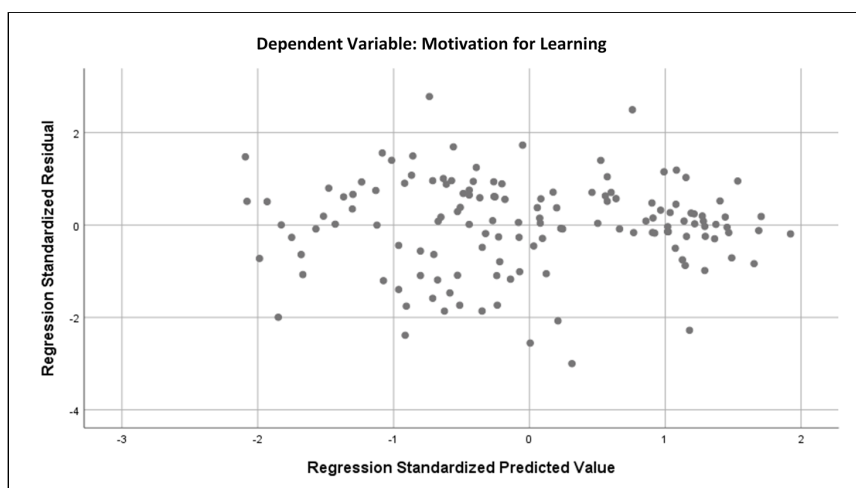

FIGURE 1 | Homogeneity of variance scatter plot

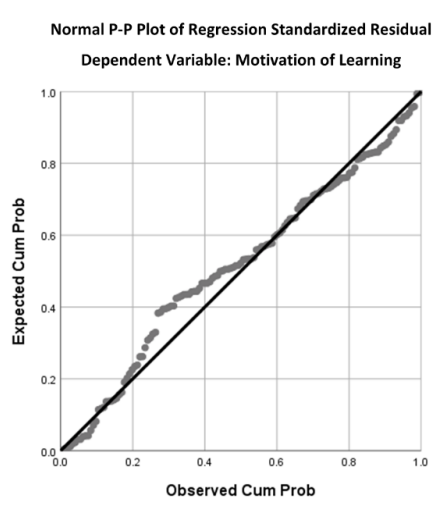

FIGURE 2 | Standard waste histogram

Figure 2 shows the PP Normal plot, which compares the observed cumulative distribution function of the standard residue versus the normal distribution function's expected cumulative distribution function. Since the plots seem to deviate very slightly from the normality line, it is appropriate to assume normality exists. The second assumption test is normality based on normally distributed model residues. Figure 3 shows a histogram of the standard residue, and the residue is somewhat in a bell curve but imperfectly.

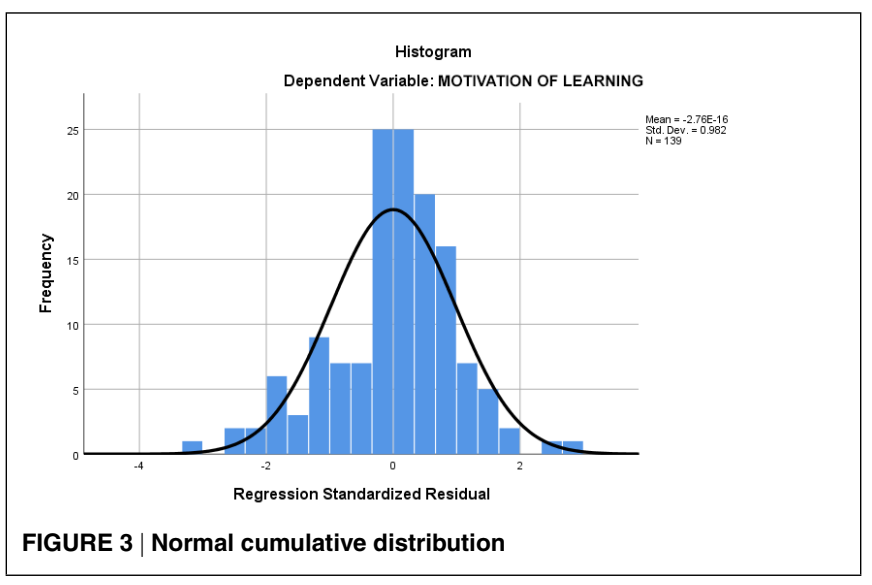

The third test is the use of the multicollinearity test when the forecast variable is closely related and affects its capacity to communicate with the results variable. In particular this means that multi-cholinearity checks, both of which appear in the Table 1 . Tolerance values are concerned where the value is less than 0.1 , when the value is greater than 0.1 , the VIF value, are important for tolerance and variance of the inflation factor (VIF, for instance). All values are considerably higher than 0.1 and all VIF values are considerably lower than 10. It can reasonably be assumed that multi-collinearity is no problem with tolerance values and VIF as it is. The score coefficients on the readiness of online learning

level and the education level are the key predictors of the AMS ranking, based on the Table ?? standard coefficients.

This research applied regression analysis and assumption testing, and this study contained three variables: online learning readiness (OLRS), online learning attitude, and academic motivation scale (AMS). The description is listed in Table 1 until Table 4 for this analysis.Figure 4 until Figure 7 is a histogram that demonstrates how the values of the three different variables contribute to the normal reference curve for each survey.

The output of Table 1 shows the number of measurements $(\mathrm{N})$, here the number of valid data for gender, education level, age, motivation learning, online learning readiness, online learning attitude is the same, namely 139 and no value is lost. Figure 4 provides a visual picture of learning motivation, which explains how it is normally distributed, precisely the distribution is in the middle position. 
TABLE 1 | Descriptive Statistics

\begin{tabular}{llllll}
\hline & & Minimum & Maximum & Mean & Std. Deviation \\
Gender & 139 & 1.00 & 2.00 & 1.3813 & .48746 \\
Level Education & 139 & 1.00 & 3.00 & 2.0000 & .81650 \\
Age & 139 & 15.00 & 23.00 & 20.1223 & 1.23041 \\
Motivation Learning & 139 & 24.00 & 85.00 & 56.0504 & 11.70057 \\
Readiness Online & 139 & 25.00 & 69.00 & 52.0504 & 7.65688 \\
Learning & & & & & \\
Attitude Online Learning & 139 & 8.00 & 24.00 & 15.7482 & 3.52649 \\
Valid N (Listwise) & 139 & & & & \\
\hline
\end{tabular}

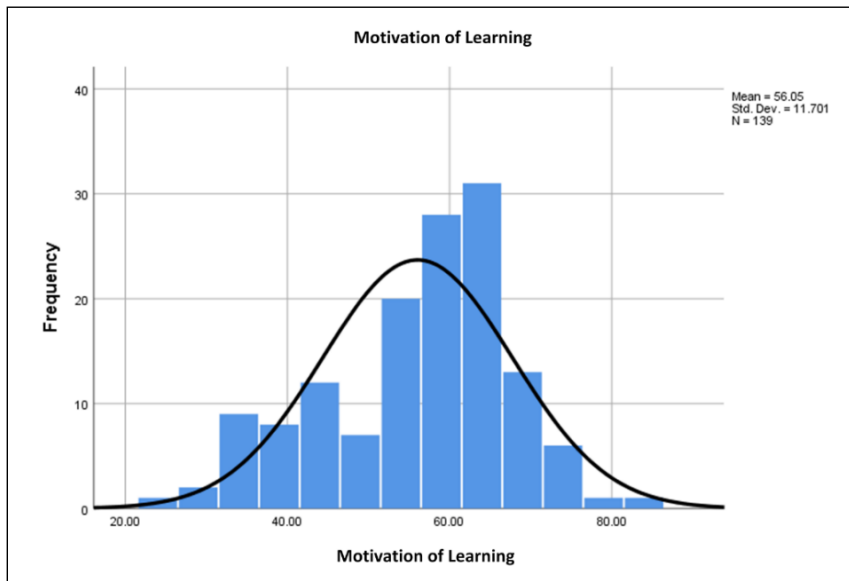

FIGURE 4 | Histogram motivation of learning

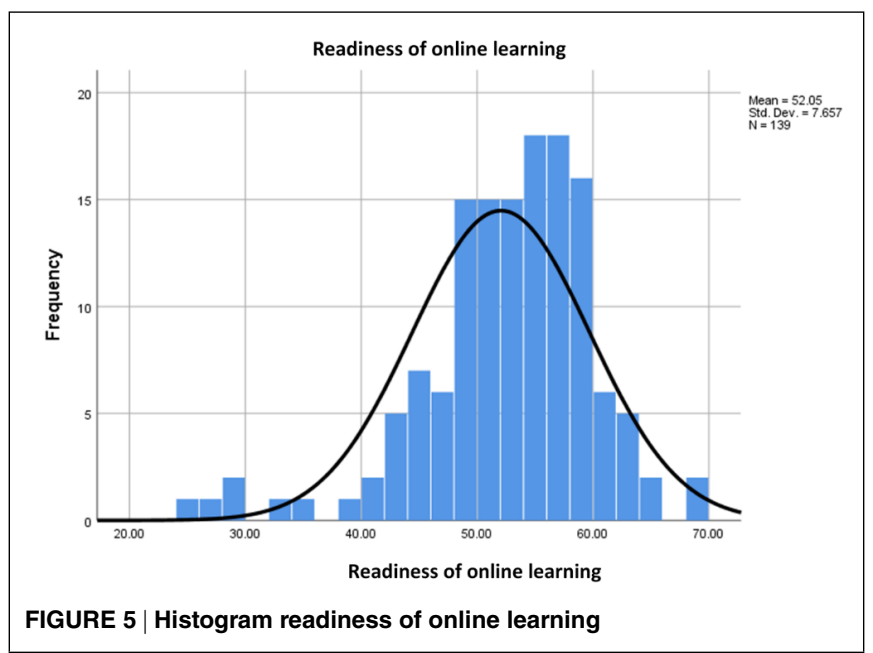

Figure 5 explains about the readiness of online learning, and the number of respondents is 139 with an average questionnaire value of 52.05.Figure 6 describes an online learning histogram's attitude with an average questionnaire value of 15.75 .

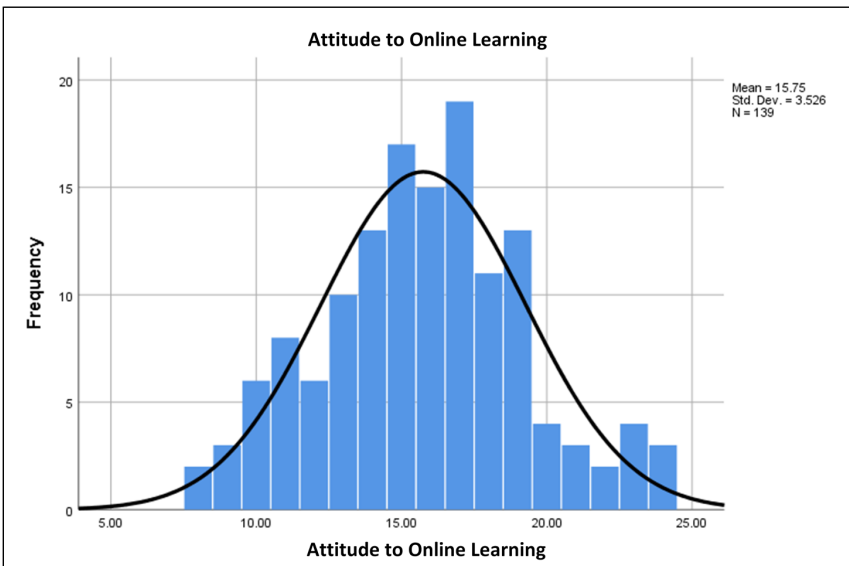

FIGURE 6 | Histogram attitude to online learning

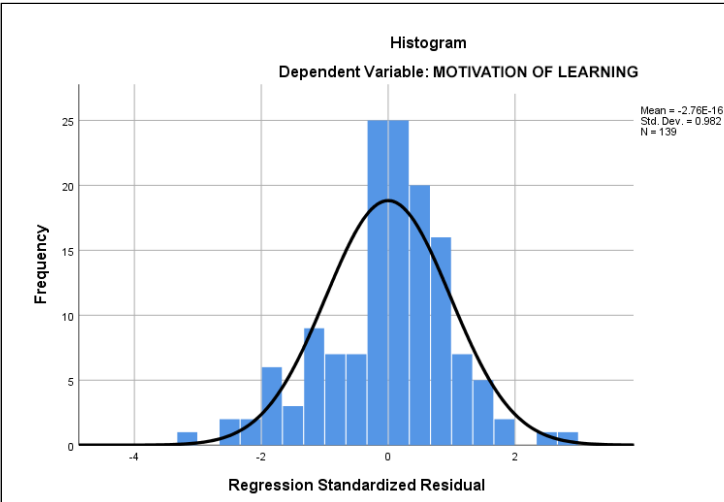

FIGURE 7 | Histogram Motivation to Online Learning

Figure 7 is a histogram motivation for learning distributed normally with an average questionnaire score of 2.76. Table 2 describes the linear regression test results showing the R-value, which symbolizes the correlation coefficient value. In the table above, the correlation value is 0.612 . This value interpreted that the relationship between the two research variables is in a strong category. The value of the determination coefficient obtained is $37.4 \%$, in which the variables have a contribution effect of $37.4 \%$ on Motivation Of Learning and $62.6 \%$ others 
TABLE 2 | Model Summary

\begin{tabular}{|c|c|c|c|c|c|}
\hline \multicolumn{6}{|c|}{ Model Summary $^{b}$} \\
\hline Model & $\mathrm{R}$ & R Square & Adjusted R Square & Std. Error of The Estimate & Durbin-Watson \\
\hline 1 & $.612 \mathrm{a}$ & .374 & .351 & 9.42957 & 1.633 \\
\hline
\end{tabular}

A. Predictors: (Constant), Attitude to Online Learning, Age, Gender, Readiness of Online Learning, Level of Education

B. Dependent Variable: Motivation of Learning

influenced by other factors.

Table 3 is used to determine the level of significance or linearity of the regression. The criteria can be determined based on the F test or the significance value test (Sig.). The easiest way is with the Sig. Test, provided that the Sig. $<0.05$, then the regression model is linear, and vice versa. Based on the third table, the Sig value is obtained. $=0.000$ which means significant criteria $(<0.05)$, thus the regression equation model based on the research data is significant, meaning that the linear regression model meets the linearity criteria. Table 5 informs the regression equation model obtained with the constant coefficients and variable coefficients in the Unstandardized Coefficients $\mathrm{B}$. Based on this table, the regression equation model is obtained: $\mathrm{Y}=34.725+0.229(\mathrm{X} 1) ; \mathrm{Y}=34,725+7,489(\mathrm{X} 2) ; \mathrm{Y}$ $=34,725+-1,147(\mathrm{X} 3) ; \mathrm{Y}=34,725+.588(\mathrm{X} 4) ; \mathrm{Y}=34,725+$ -.186 (X5)

Results concerning demographic variables, including the rank structure of Aviation Polytechnic cadets, showed inversely proportional effects. The rank and increase of responsibilities as aviation polytechnic cadets at the time the get promoted confirmed a person downgrade finding. Increased enthusiasm for online learning exists only in cadets with more time and less obligation. This finding explains the extension of the relationship between educational level differences directly linked to the ranking as the level of education is the first factor excluded from the model and has effects that are inversely proportional to the model rankings. The remaining age was an insignificant indicator of online learning motivation to strengthen technical skills perceptions of diversity between generations Dündar and Akçayir (2014). Previous research found no correlation between the problems of online learning and the age of schooling. Online learning also allows cadets to take responsibility for their learning. Each cadet must enter the online classroom on their initiative. Then they will find comments from the instructor and other classmates. Therefore, intrinsic motivation is necessary to complete online courses. The power of energy in individual interests illustrates intrinsic motivation.

The study results indicate that online learning attitude ratings, readiness scale scales of online learning, age, gender, and level of education showed significant predictor results for AMS ratings. The educational level and the ability to learn online are essential variables in AMS. The ability to get academic encouragement online as a significant factor in the online world is linked to the outcome of the study Suri (2016). In this analysis, constructing an age is inconsistent with others who find no connection between problems of age and online learning. The findings of this study, however, show that there is a negative correlation of age perceptions with technical skills (CIGDEM, 2014) Buzdar et al. (2016).

No previous studies have reported that a significant indicator of academic motivation is the education level. Gender is not a significant indicator because there was no association between gender and online learning difficulties, which is consistent with the findings of Suri (2016). However, no earlier studies indicate years of service or schooling as a possible academic motivation indicator. Academic motivation predicts readiness and graduation levels in online learning. The study findings support the results of negative attitudes that harm cadets in online environments. Cadets have no positive attitude about online learning English for Aviation Polytechnic due to the high level of difficulty in understanding and using online learning programs without having appropriate guidelines. If student accessibility is made easy for online learning, cadets' attitudes to online learning may develop according to their use Durksen et al. (2016).

This research recommends improving the interaction between students and learning materials, students and instructors, and online learning between students. This research shows that online courses are more rigorous, that cadets need to read and work than expected Phillips et al. (2015). Other characteristics of online courses are that the students have to be more responsible for their learning, take the initiative to enter online classes, and perform tasks rather than sitting in classrooms and listening to teachers. This research also demonstrates that students usually do not miss teacher interactions and do not lack teacher feedback. The results of this study show that students receive more meaningful information and learn more than they expect in online courses. 
TABLE 3 | Anova

\begin{tabular}{|c|c|c|c|c|c|}
\hline \multicolumn{6}{|l|}{ Anova $^{a}$} \\
\hline Model & Sum of Squares & Df & Mean Square & $\mathrm{F}$ & Sig. \\
\hline $\begin{array}{l}\text { Regres- } \\
\text { sion }\end{array}$ & 7066.719 & 5 & 1413.344 & 15.895 & $.000 \mathrm{~b}$ \\
\hline Residual & 11825.929 & 133 & 88.917 & & \\
\hline Total & 18892.647 & 138 & & & \\
\hline \multicolumn{6}{|c|}{ A. Dependent Variable: Motivation Of Learning } \\
\hline \multicolumn{6}{|c|}{$\begin{array}{l}\text { B. Predictors: (Constant), Attitude to Online Learning, Age, Gen- } \\
\text { der, Readiness of Online Learning, Level of Education }\end{array}$} \\
\hline
\end{tabular}

TABLE 4 | Regression Model Coefficients

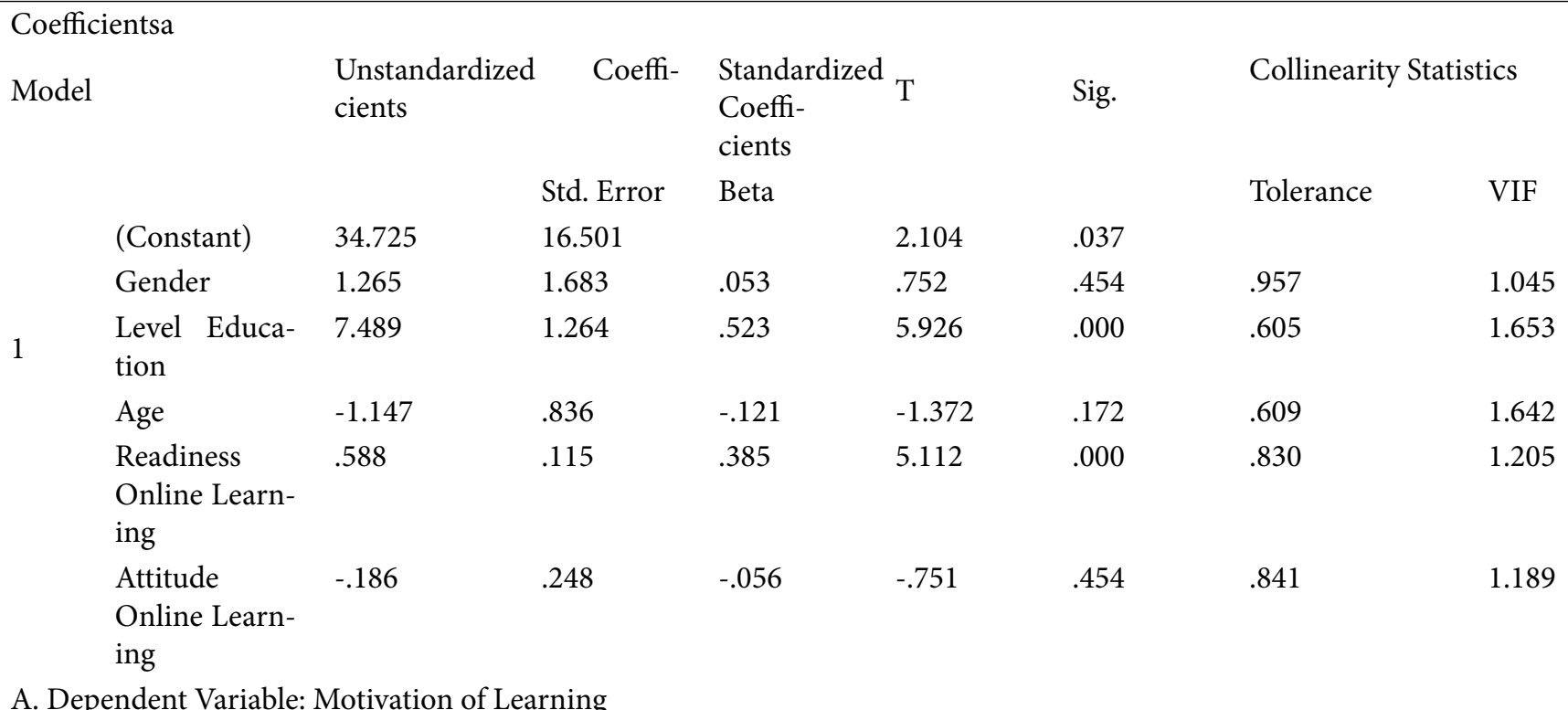

\section{CONCLUSION}

Results of the present research show that grade level and readiness of online learning are significant contributors to motivation for cadets to learn online. The findings can be clarified by correlating variations in education levels with the ranking in particular since the education level is the first factor excluded from the model, with findings inverse to the ranking of the model. The rest of the age as a predictive measure of on-line learning motivation increases the contrast between expectations of technical skills. Second, the research shows that readiness of online learning is important for influencing the motivation of cadet learning online. Training in an online learning environment is important. Educational institutions need to prioritize online learning experiences before learning to deal more efficiently with the problem of on-line learning motivation. An unexpected finding from the results of this study is that readiness for online learning does not occur as the most expected significant predictor. The contribution of this research is key to enhancing online learning output for cadets in addressing the online learning motivation issue, while educational institutions may use online learning as the most successful learning platform.

The results of this work will help educational institutions determine the best approaches for learning to efficiently meet the learning needs of cadets. Inability to resolve this problem will hamper cadet development, because they are unable to adapt to up-to-date online learning for training and education. The results of this study should be expanded in the future, not only in the sense of mixed learning, by extending this research approach to a broader representation.

This research purpose is in education, which is specialized in semi-military inclusive work, not in commercial organizations. Potential researchers must explicitly investigate AMS and OLRS without using online learning behavior, or age, to evaluate the motivation of online learning. The recommendation for further research is to add cognitive and meta cognitive learning strategy variables. The addition of this variable can improve the learning outcomes of cadets. 


\section{ACKNOWLEDGEMENTS}

This research was partially supported by Politeknik Penerbangan Surabaya, Indonesia. Authors thank their colleagues from

\section{REFERENCES}

Al-Rahmi, W. M. (2019). Integrating Technology Acceptance Model with Innovation Diffusion Theory: An Empirical Investigation on Students' Intention to Use E-Learning Systems. IEEE Access.

An, Y. (2018). The effects of an online professional development course on teachers' perceptions, attitudes, self-efficacy, and behavioral intentions regarding digital game-based learning. Educational Technology Research and Development.

Bovermann, K., Weidlich, J., and Bastiaens, T. (2018). Online learning readiness and attitudes towards gaming in gamified online learning - a mixed methods case study. International Journal of Educational Technology in Higher Education 15. doi: 10.1186/s41239-018-0107-0.

Buzdar, M. A., Ali, A., and Tariq, R. U. H. (2016). Emotional Intelligence as a Determinant of Readiness for Online Learning. The International Review of Research in Open and Distributed Learning 17, 17-17. doi: 10.19173/irrodl.v17i1.2149.

Çakır, N. K., , and and, G. G. (2019). The Role of Metacognitive Awareness and Motivation of Prospective Primary School Teachers in Predicting Their Academic Achievement in the 'Science and Technology Laboratory Applications'; Course. International Journal of Progressive Education 15, 28-43. doi: 10.29329/ ijpe.2019.193.3.

Dündar, H. and Akçayir, M. (2014). Implementing tablet \{PCs\} in schools: Students' attitudes and opinions. Computers in Human Behavior. Elsevier $\{B V\}$ 32, 40-46.

Durksen, T. L., Chu, M.-W., Ahmad, Z. F., Radil, A. I., and Daniels, L. M. (2016). Motivation in a MOOC: a probabilistic analysis of online learners' basic psychological needs. Social Psychology of Education 19, 241-260. doi: 10.1007/s11218015-9331-9.

Gay, G. H. E. (2016). An assessment of online instructor e-learning readiness before, during, and after course delivery. Journal of Computing in Higher Education 28, 199-220. doi: 10.1007/s12528-016-9115-z

Harrison, R. (2017). A Cross-Sectional Study to Describe Academics Confidence, Attitudes, and Experience of Online Distance Learning in Higher Education. Journal of Educators Online. Grand Canyon University 14.

Hung, M. L. (2010). Learner readiness for online learning: Scale development and student perceptions. Computers and Education.

Ilgaz, H. and Gülbahar, Y. (2015). A snapshot of online learners: e-Readiness, eSatisfaction and expectations. The International Review of Research in Open and Distributed Learning 16. doi: 10.19173/irrodl.v16i2.2117.

Kaftan, O. J. and Freund, A. M. (2019). A motivational perspective on academic procrastination: Goal focus affects how students perceive activities while procrastinating. Motivation Science 5, 135-156. doi: 10.1037/mot0000110.

Kebritchi, M., Lipschuetz, A., and Santiague, L. (2017). Issues and Challenges for Teaching Successful Online Courses in Higher Education. Journal of Educational Technology Systems 46, 4-29. doi: 10.1177/0047239516661713.

Kolekar, S. V., Pai, R. M., and M.M., M. P. (2018). Adaptive User Interface for Moodle based E-learning System using Learning Styles. Procedia Computer Science 135, 606-615. doi: 10.1016/j.procs.2018.08.226.

Lieharyani, D. C., Ginardi, R. V. H., Ambarwati, R., and Multazam, M. T. (2019). Assessment for good university governance in higher education focus on align
Universitas Muhammadiyah Sidoarjo who provided insight and expertise that greatly assisted the research, although they may not agree with all of the interpretations of this paper.

strategy business with it at big data era. Journal of Physics: Conference Series 1175 , 012204-012204. doi: 10.1088/1742-6596/1175/1/012204.

Nanayakkara, C. (2007). A Model of User Acceptance of Learning Management Systems. The International Journal of Learning: Annual Review 12, 223-232. doi: 10.18848/1447-9494/cgp/v13i12/45146.

Panigrahi, R., Srivastava, P. R., and Sharma, D. (2018). Online learning: Adoption, continuance, and learning outcome-A review of literature. International Journal of Information Management 43, 1-14. doi: 10.1016/j.ijinfomgt.2018.05.005.

Parker, P. C. (2018). An attribution-based motivation treatment for low control students who are bored in online learning environments. Motivation Science.

Phillips, B. N., Turnbull, B. J., and He, F. X. (2015). Assessing readiness for selfdirected learning within a non-traditional nursing cohort. Nurse Education Today 35, e1-e7. doi: 10.1016/j.nedt.2014.12.003.

Prior, D. D. (2016). Attitude, digital literacy and self efficacy: Flow-on effects for online learning behavior. The Internet and Higher Education 29, 91-97.

Saeedi, M., Rafii, F., and Parvizy, S. (2019). Academic motivation in nursing students: A hybrid concept analysis. Iranian Journal of Nursing and Midwifery Research 24, 315-315. doi: 10.4103/ijnmr.ijnmr_177_18.

Suri, G. (2016). Factors Influencing E-learning among University Students. International Journal of Marketing and Business Communication. Publishing India Group 5.

Titrek, O., Cetin, C., Kaymak, E., and Kașikçi, M. M. (2018). Academic Motivation and Academic Self-efficacy of Prospective Teachers. Journal of Education and Training Studies 6, 77-77. doi: 10.11114/jets.v6i11a.3803.

Vallerand, R. J., Pelletier, L. G., Blais, M. R., Briere, N. M., Senecal, C., and Vallieres, E. F. (1992). The Academic Motivation Scale: A Measure of Intrinsic, Extrinsic, and Amotivation in Education. Educational and Psychological Measurement 52, 1003-1017. doi: 10.1177/0013164492052004025.

Wong, K. T., Muhammad, M. M. B., and Abdullah, N. B. (2020). Exploring the drivers of intention to use interactive whiteboards among Malaysia university students: Does technology self-efficacy matter? International Journal of Emerging Technologies in Learning.

Yilmaz, R. (2017). Exploring the role of e-learning readiness on student satisfaction and motivation in flipped classroom. Computers in Human Behavior.

Conflict of Interest Statement: The authors declare that the research was conducted in the absence of any commercial or financial relationships that could be construed as a potential conflict of interest.

Copyright (c) 2021 Rochmawati, Fatmawati, Maharani Sukma and Sonhaji. This is an open-access article distributed under the terms of the Creative Commons Attribution License (CC BY). The use, distribution or reproduction in other forums is permitted, provided the original author(s) and the copyright owner(s) are credited and that the original publication in this journal is cited, in accordance with accepted academic practice. No use, distribution or reproduction is permitted which does not comply with these terms. 